\title{
Numerical analysis of an elastomeric bearing pad by hyperelastic models
}

\author{
Rivania Cristina Rezende (Main Author)
}

Department of Structural Engineering, Universidade Federal de Minas Gerais

Av. Antônio Carlos 6627, Belo Horizonte 31270-901, MG (Brazil)

rivaniarezende@yahoo.com.br

https://orcid.org/0000-0001-6625-1388

Marcelo Greco (Corresponding Author)

Department of Structural Engineering, Universidade Federal de Minas Gerais

Av. Antônio Carlos 6627, Belo Horizonte 31270-901, MG (Brazil)

mgreco@dees.ufmg.br

https://orcid.org/0000-0001-5500-0225

\section{Debora Francisco Lalo}

Department of Structural Engineering, Universidade Federal de Minas Gerais

Av. Antônio Carlos 6627, Belo Horizonte 31270-901, MG (Brazil)

debora.lalo@yahoo.com.br

https://orcid.org/0000-0003-4184-2469

Manuscript Code: 13824

Date of Acceptance/Reception: 23.11.2020/19.03.2020

DOI: 10.7764/RDLC.19.3.301

\section{Abstract}

Elastomeric bearing pads are responsible for transfering loads at the junction between beams and columns of bridges and viaducts, providing restrict freedom of movement in the superstructure. The elastomeric material of bearing pads is a synthetic rubber reinforced with carbon black particles and subjected to a process of vulcanization, also represented by hyperelastic material models based on strain energy density functions. The objective of the present paper is to use the finite element analysis software Abaqus to select the most appropriate hyperelastic model, as well as its constants, applying them to a bearing pad installed in an existing viaduct, evaluating its behavior and the displacements resulting from the application of usual loads. A data fitting procedure is performed through the finite elements analysis software to obtain the Neo-Hooke, Arruda-Boyce and Yeoh model constants. The proposed methodology presents results that are coherent when compared to technical specification limits for available bearing pads products.

Keywords: elastomeric bearing pad, bridges, deformation, hyperelastic model, finite elements.

Introduction

Bearing pads are devices installed between the beams and the fixed parts (columns) of bridges and viaducts, being responsible for transfering permanent loads associated with the structure's weight and traffic. They also accommodate displacements associated with vehicle braking and thermal expansion, avoiding the lateral transfer of loads to columns in addition to accommodating inclinations on beams caused by wind effects or bending (Gent, 2012).

There are several types of support equipment, manufactured with different materials and varied forms. The selection of the appropriate typology depends on functional characteristics and the magnitude of loads verified in design. Elastomeric bearing pads stand out for their availability, durability and low cost. The association of rubber and steel settled in intermediate layers increases compressive and rotational stiffness, controlling vertical deflection and restricting the rubber bulging (Stanton \& Roeder, 1982).

Among the technologies developed to increase the strength and durability of rubber, the development of synthetic rubber, such as neoprene (polychloroprene), the addition of reinforcement materials, such as carbon black particles and molecular restructuring processes, such as vulcanization, extended the use of rubber for other sectors, like structural engineering.

Rubber shows considerable deformations when loaded and returns to its original shape after removing the load, without volume changes. Thus, rubber is a hyperelastic material that shows a non-linear behavior of which complexity of characterization requires the use of constitutive equations developed through empirical material observations and formulated through strain energy functions $(W)$ assuming the material as incompressible under quasi-static conditions. 
Recent studies related to numerical analyses and simulations of circular bearing pads include Kalfs et al. (2016) and Huang et al. (2019), where the stress and strain that are displayed in the simulations are analyzed.

The elastomers in structures are also adopted in regions subject to earthquakes. Studies about its use in bridges are contained in works of Shuijiang (2019) and Huang et al. (2018). Comparisons of seismic responses in a building with and without the insertion of rubber bearings with high damping are shown in Islam (2017).

Description of the Problem

\section{Hyperelastic models}

The formulations used to represent elastomeric materials are not developed using the rheological deformation, but by the strain energy. Since the 1940 studies of Treloar, several hyperelastic models based on strain energy functions were developed to estimate and to provide a better accuracy in response to each deformation mode. The models developed by Mooney (1940), Treloar (1943), Valanis \& Landel (1967), Ogden (1972), Arruda-Boyce (1993) and Yeoh (1993), among others.

The constitutive laws related to hyperelastic models are given by classical elasticity with the nominal deformations ( $\left.\varepsilon_{i j}\right)$, the principal stretches $\left(\lambda_{i}\right)$, which compose the deformation gradient tensor $\left(F_{i k}\right)$ and the right $\left(C_{i k}\right)$ and left $\left(B_{i k}\right)$ CauchyGreen deformation tensor as demonstrated in Treloar (19750). Tensors $C_{i k}$ and $B_{i k}$ are symmetrical and admit three main invariants, denoted as $I_{1}, I_{2}$ and $I_{3}$, by the following equations:

$$
\begin{gathered}
I_{1}=\lambda_{1}^{2}+\lambda_{2}^{2}+\lambda_{3}^{2} \\
I_{2}=\lambda_{1}^{2} \lambda_{2}^{2}+\lambda_{2}^{2} \lambda_{3}^{2}+\lambda_{1}^{2} \lambda_{3}^{2} \\
I_{3}=J=\lambda_{1}^{2} \lambda_{2}^{2} \lambda_{3}^{2}
\end{gathered}
$$

The function $W$ is based on invariants or stretches as follows:

$$
W=f\left(I_{1}, I_{2}, I_{3}\right) \vee W=f\left(\lambda_{1}, \lambda_{2}, \lambda_{3}\right)
$$

Applying the incompressibility condition, the third invariant becomes equal to the unity. Adopting the use of subscribed bars for differentiation of the invariants after the application of incompressibility, the first and second invariant can be expressed as follows:

$$
\begin{gathered}
\bar{I}_{1}=\bar{\lambda}_{1}^{2}+\bar{\lambda}_{2}^{2}+\bar{\lambda}_{3}^{2} \\
\bar{I}_{2}=\bar{\lambda}_{1}^{(-2)}+\bar{\lambda}_{2}^{(-2)}+\bar{\lambda}_{3}^{(-2)}
\end{gathered}
$$

Finally, the separation of function $W$ in $W_{d}$ (associated to shape changes) and $W_{V}$, (associated with volume changes).

$$
W=W_{d}\left(\bar{I}_{1}, \bar{I}_{2}\right)+W_{V}(J) \vee W=W_{d}\left(\bar{\lambda}_{1}, \bar{\lambda}_{2}, \bar{\lambda}_{3}\right)+W_{V}(J)
$$

The main stretches are expressed as:

$$
\bar{\lambda}_{i}=J^{\frac{-1}{3}} \lambda_{i} ; i=1,2,3
$$

For larger deformations, as reported in (Ogden R. W., 1984), the stress tensor $\left(\sigma_{i j}\right)$ is given by the following equation:

$$
\sigma_{i k}=\frac{\partial W}{\partial F_{i k}}-p F_{i k}^{-1} ; i, k=1,2,3
$$

where the first term is related to the deviatoric stress associated with shape changes, and $p$ is related to hydrostatic pressure associated with volume changes.

Through that Theory, some classical models stand out among several others that were developed and can be separated into two groups: 
- Neo-Hooke:

$W=C_{10}\left(\bar{I}_{1}-3\right)+\frac{1}{D_{1}}(J-1)^{2} ;$ where $\mu_{0}=2 C_{10}$

- Yeoh:

$W=\sum_{i=1}^{N} C_{i 0}\left(\bar{I}_{1}-3\right)^{i}+\sum_{k=1}^{N} \frac{1}{D_{k}}(J-1)^{2 k} ;$ where $\mu_{0}=2 C_{10}$

b Micromechanical models (based on length of molecular chains, chemical link types and number of crosslinks observed on material):

- Arruda-Boyce:

$W=\mu \sum_{i=1}^{5} \frac{C_{i}}{\lambda_{L}^{2 i-2}}\left(\bar{I}_{1}^{i}-3^{i}\right)+\frac{1}{D}\left(\frac{J^{2}-1}{2}-\ln J\right) ;$ where $\mu_{0}=\mu \sum_{i=1}^{5} i \frac{C_{i}}{\lambda_{L}^{2^{(i-1)}}} 3^{(i-1)}$

where the constants $C_{i}$, are:

$C_{1}=\frac{1}{2} ; C_{2}=\frac{1}{20} ; C_{3}=\frac{11}{1050} ; C_{4}=\frac{19}{7000} ; C_{5}=\frac{519}{673750}$

State of the Art

Mechanical behavior of elastomers is very important for various areas of engineering, such as automotive (Lee et al., 2017), medicine (Cardoso et al., 2018), civil construction (Al-anany and Tait, 2017; Gauron et al., 2018), among others.

Hyperelastic material models have been developed and implemented in the most common computational codes. Some recent reviews of constitutive models can be found in Mansouri et al. (2017). Since several industrial applications require high strain levels, it is important to deal with experimental results obtained from solids that undergo large strains, as can be seen in some recent works such as Cao et al. (2017).

\section{Obtaining the constants}

In order to obtain the constants associated with each constitutive model, experimental tests are carried out with rubber samples in which modes of pure deformation are induced from the application of loads and observation of displacements. Pure deformation refers to a condition where stress does not vary with the positions. The tests used in the study are uniaxial tension, equibiaxial tension and planar tension (pure shear), as demonstrated in Figure 1 , as well as their principal stretches. The procedures for the tests are available in (Miller, 2004) and the only standard version is for the uniaxial tension, through (ASTM, 2016).

Figure 1. Schematics of uniaxial tension, equibiaxial tension and pure shear and the main stretches. Source: Adapted from Berselli, Vertechy, \& Pellicciari (2011).

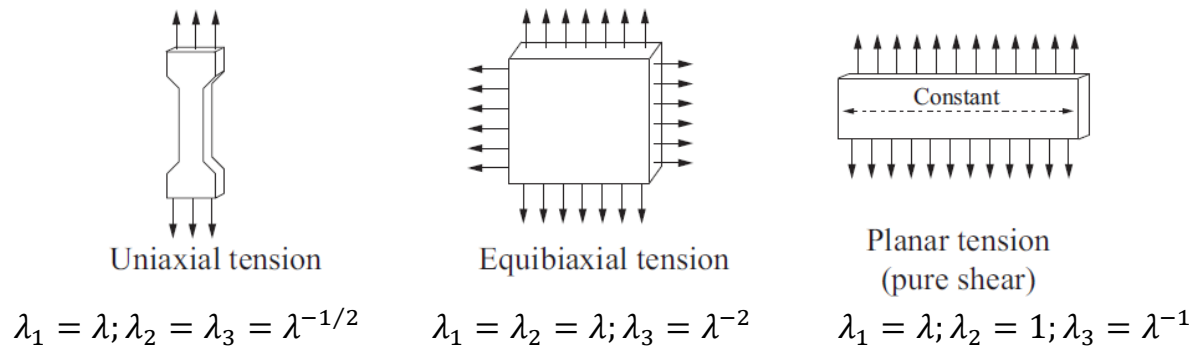

The force-displacement test readings converted into stress-strain ratios, which are used for the data fitting phase performed through finite elements analysis software Abaqus ${ }^{\oplus}$.

According to Simulia (2013), to manage hyperelastic constants, test data is processed through linear procedure of leastsquares fit. Where for " $n$ " data pairs of nominal stress and strain, the relative error $E r$ measurement is minimized by the equation: 


$$
E r=\sum_{i=1}^{n}\left(1-T_{i}^{t h} / T_{i}^{t e s t}\right)^{2}
$$

where $T_{i}^{t h}$ is the value of stress obtained in the experimental test and $T_{i}^{t h}$ is the theoretical stress of data fitting. This procedure covers all strain energy functions available in the software, in any $N$ order.

Each model has a number of specific constants depending on the Norder of the functions. On the other hand, the stress during data fitting depends on the relationship between the principal stretches as follows:

- Uniaxial:

- Equibiaxial:

$$
\sigma=2\left(\lambda-\frac{1}{\lambda^{2}}\right)\left(\frac{\partial W}{\partial I_{1}}+\frac{1}{\lambda} \frac{\partial W}{\partial I_{2}}\right)
$$

- $\quad$ Pure shear:

$$
\sigma=2\left(\lambda-\frac{1}{\lambda^{5}}\right)\left(\frac{\partial W}{\partial I_{1}}+\lambda^{2} \frac{\partial W}{\partial I_{2}}\right)
$$

$$
\sigma=2\left(\lambda-\frac{1}{\lambda^{3}}\right)\left(\frac{\partial W}{\partial I_{1}}+\frac{\partial W}{\partial I_{2}}\right)
$$

Despite equibiaxial and pure shear tests not being used in the present study, it is important to point out their importance in rubber characterization, despite the absence of technical codes about them. Thus, the focus here is to apply a methodology, using three constitutive rubber models (Neo-Hooke, Arruda-Boyce and Yeoh), for numerical modeling of real elastomeric bearing pads based on the only currently available standard test (ASTM, 2016).

\section{Compressibility}

For almost incompressible materials, such as rubbers $(v \approx 0,5)$, volumetric test is recommended to obtain the material Poisson ratio $(v)$. The codes used in the software Abaqus require the use of a certain degree of compressibility for code processing (Simulia, 2013). If the volumetric test is not available, it is possible to adopt a relative compressibility of a material by the ratio of its initial bulk modulus $\left(k_{0}\right)$ and the initial shear modulus $\left(\mu_{0}\right)$ as bellow:

$$
\frac{k_{0}}{\mu_{0}}=\frac{2(1+v)}{3(1-2 v)}
$$

For reinforced carbon black rubbers, when the parts are not confined, Abaqus manual guides the selection of relative compressibility between 50 and 200 ( $v$ between 0.490 and 0.4975 ) in order to obtain more accurate responses in simulations.

The equation part associated with compressibility in each model $\left(D_{1}\right)$ obtained with Poisson's ratio $v$ and its initial shear modulus $\mu_{0}$ is given by the equation:

$$
D_{1}=\frac{2}{k_{0}}=\frac{3(1-2 v)}{\mu_{0}(1+v)}
$$

\section{Methodology}

To realize a finite element analysis in elastomeric bearing pads using the hyperelastic models, it is necessary to characterize the rubber by experimental test results. In this study, the responses obtained in the uniaxial tension test, performed by a bearing pad manufacturer, were used for the procedure of data fitting through finite element method via Abaqus ${ }^{\oplus}$ software. Despite the importance of other non-standard tests related to pure deformation states, for the specific application presented here, the characterization of the material using only uniaxial tension test is satisfactory.

Among the options of classic models available in software for data fitting, the Neo-Hooke, Yeoh ( $N=3$ ) and Arruda-Boyce models were selected. According to Marlow (2013), constitutive models that depend only on the first invariant, as the three selected models, can be completely defined using responses from only one experimental test, such as the uniaxial tension.

For finite elements used to represent the elastomeric material, it is necessary to use the hybrid formulation Lalo et al. (2019). Such formulation avoids volume strain locking (common in materials with $v \approx 0.5$ ) that could block the finite element mesh from adequately performing the incompressible material deformations, leading to incorrect solutions. 
Regarding the steel layers, reduced integration is adopted, avoiding the locking associated with excessive rigidity resulting from an integration using all the nodes of elements. To avoid mesh instability associated with deformation spurious modes, the Hourglass control function is activated on mesh to minimize such instability.

Finite Element hybrid formulation considers independent interpolation functions for displacements and stress fields. The number and the position of nodal points used to describe these two fields are different. It is a very suitable formulation for large strains modeling. In the theory of hybrid formulation, pressure (surface force) is treated as an uncoupled variable and, therefore, must receive a suitable formulation through the weak form of the Finite Element Method. All the finite elements adopted are eight-node brick type (C3D8), with their proper terminations associated with the numerical solution required for each material. Considering the hybrid formulation in rubber and reduced integration in steel as previously reported, the elements adopted for materials are C3D8H and C3D8R, respectively.

Discretization of the mesh was defined through a preliminary analysis of mesh refinement, in order to ensure the accuracy of results with less computational difficulty (Tavares, 1998). The NLgeom function of software was also activated to consider the effects related to geometric non-linearity involved with large deformations analysis.

The elastomeric bearing pad used in this study has dimensions $500 \times 600 \times 130(\mathrm{~mm})$ and was implanted in a highway viaduct. The initial design considerations that guide geometry and configuration of bearing pads involve the relationship between compression load and its contact area, relating them to the normative limitations of compression stresses. The form factor, which relates its contact area with the lateral surface of the rubber layer, is another relevant factor that affects the behavior of the set.

Bearing pads manufacturers usually provide pre-dimensioning tables where, from the pre-selected area, it is possible to identify possible configurations related to the number and thickness of steel and elastomer layers.

Normally, after selecting the possible configuration, calculations are performed to verify displacements, distortions and stability of the set, ensuring that the expected results do not exceed limit values guided by standards. The information associated with geometry and loading defined in project after all these considerations is shown in Table 1.

Table 1. Geometry and loading of the elastomeric bearing pad. Source: Developed by the author.

\begin{tabular}{ccccc}
\hline \multicolumn{2}{c}{ Geometric characteristics of the layers } & \multicolumn{2}{c}{ Loads } \\
\hline Type & Quantity & $\begin{array}{c}\text { Thickness } \\
(\mathrm{mm})\end{array}$ & Type & $\begin{array}{c}\text { Load } \\
(\mathrm{kN})\end{array}$ \\
\hline Covers & 2 & 3 & Vertical & 3529.8 \\
Steel Layers & 9 & 4 & Longitudinal & 36.1 \\
Rubber Layers & 8 & 11 & Lateral & 28.3 \\
\hline
\end{tabular}

For the modeling, supporting steel plates were adopted in the lower and upper faces of the bearing pad to represent the connection with viaduct columms and beams. At the lower surface, total movement restriction was admitted as boundary condition, admitting the columns of the structure as rigid and not admitting lateral efforts transmitted by the viaduct beams. At the upper face, the movement freedom of all axis is allowed, where a Multi-point constraint - MPC restriction was admitted. In this type of restriction, a single point (RP - Reference Point) is used to restrict the movement of slave nodes from a specific part based on the movement of a single point. This point was considered as vertically $10 \mathrm{~mm}$ above the bearing pad geometric center, and the same was used for the application of the loads through distinct and cumulative steps between them.

In the first step, vertical loading (y) associated with the structure's own weight and the traffic was considered. The second step regards longitudinal loading ( $\mathrm{z}$ ) associated with the thermal expansion and vehicles' braking effects. Finally, the third step regards the transversal efforts $(x)$ representing the forces associated with wind on the structure. The Figure 2 represents the viaduct outline with the bearing pad, as well as its geometric and loading configuration. 
The use of evaluate material featured in the Abaqus ${ }^{\circledR}$ software allows to visualize the expected behavior in material associated with each formulation, in order to guide the choice of appropriate model (Simulia, 2013).

In Figure 3, it is possible to verify the curves obtained in the selected models, as well as the curve obtained by uniaxial test.
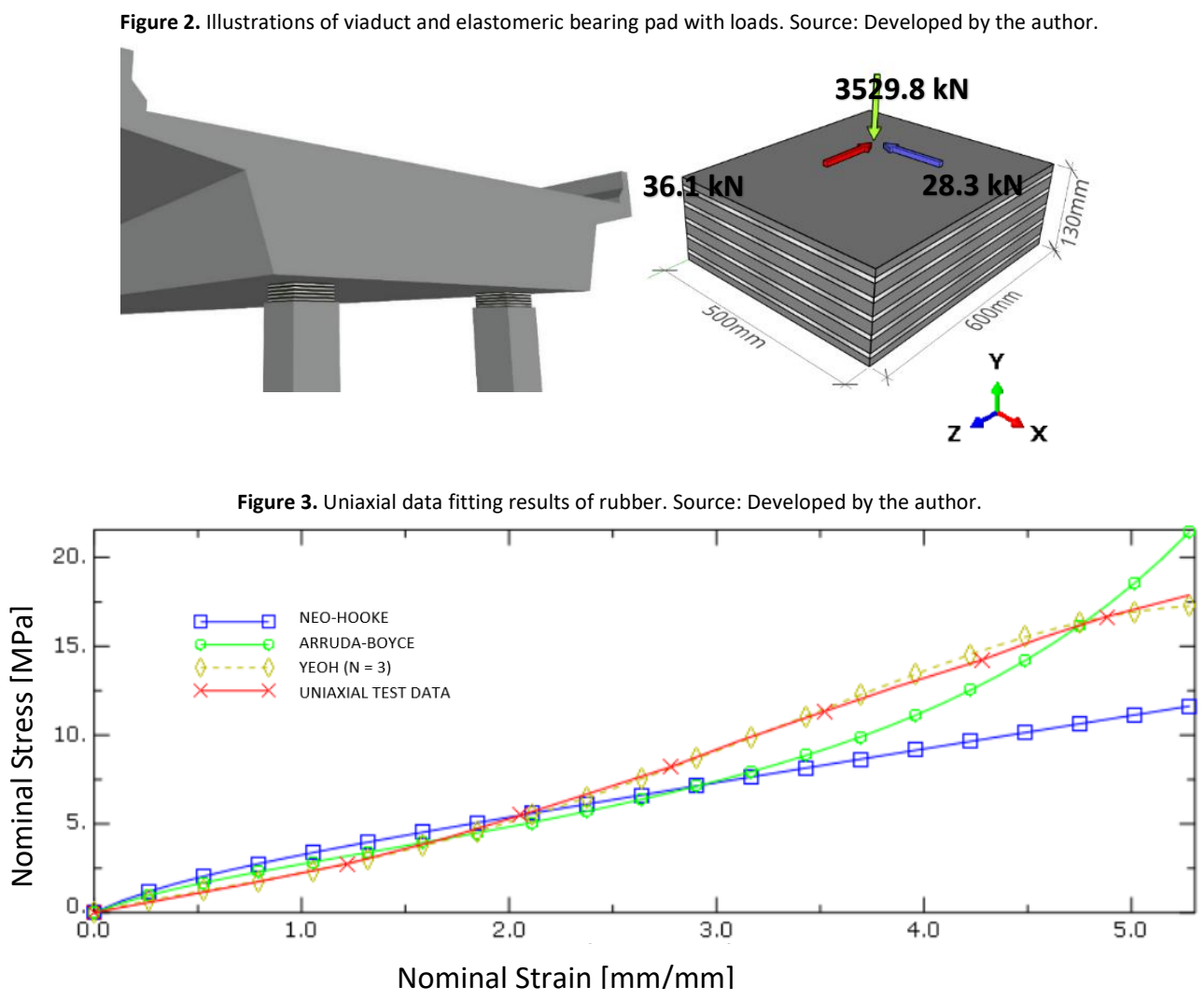

Yeoh model had a better fit in the analysis, with an error smaller than $1 \%$ in the curves adjustment by least-squares method. Neo-Hooke model presented the highest variation, especially when the sample presented large deformations.

The constitutive model selected is Yeoh $(\mathrm{N}=3)$, whose constants obtained by the process are: $\mathrm{C}_{10}=0.605 / \mathrm{C}_{20}=0.0249$ $/ C_{30}=-0.00025$. The adopted constant associated with compressibility, following the guidelines of the software's user manual (with relatie compressibility material, obtained by the equation 19 as equal to 200) was $v=0.4975$, resulting in $\mathrm{D}_{1}=0.0083$. For steel plates, the elastoplastic model was adopted with constants $E=210 \mathrm{GPa}, v=0.3$ and $\mathrm{f}_{\mathrm{yk}}=235 \mathrm{MPa}$.

By using the mesh refinement analysis, a model composed of 201498 finite elements was adopted, with 448165 nodes, totaling 1143474 variables that cost more than 600 minutes of processing by the software on a machine with an Intel Core i7-8565U 8th generation processor, with Windows 10 64-bit operating system. The machine's Random Access Memory (RAM) is $16 \mathrm{~GB}, \mathrm{DDR} 4,2666 \mathrm{MHz}$, with a $128 \mathrm{~GB}$ SATA M.2 solid-state drive (SSD) and 1 TB, 5400RPM SATA hard drive (HDD).

At the end of the first step, vertical loading produced a displacement of $5.87 \mathrm{~mm}$ in the bearing pad, with maximum stress reaching $50.472 \mathrm{MPa}$ in steel and $1.99 \mathrm{MPa}$ in rubber. After the second step, there was a longitudinal displacement of $10.36 \mathrm{~mm}$, with maximum stress reaching $50.576 \mathrm{MPa}$ in steel and $2.86 \mathrm{MPa}$ in rubber. Finally, at the end of the third step, where all expected loads were acting on the bearing pad, there was an $8.43 \mathrm{~mm}$ offset in the transverse direction, with maximum stresses reaching $50.654 \mathrm{MPa}$ in steel and $2.86 \mathrm{MPa}$ in rubber. Figure 4 represents the mapping of the final equivalent von Mises stresses. 
Figure 4. Equivalent von Mises stress (MPa) mapping in the middle section of the bearing pad after loading of step 1 (a), step 2 (b) and step 3 (c). Source: Developed by the author.
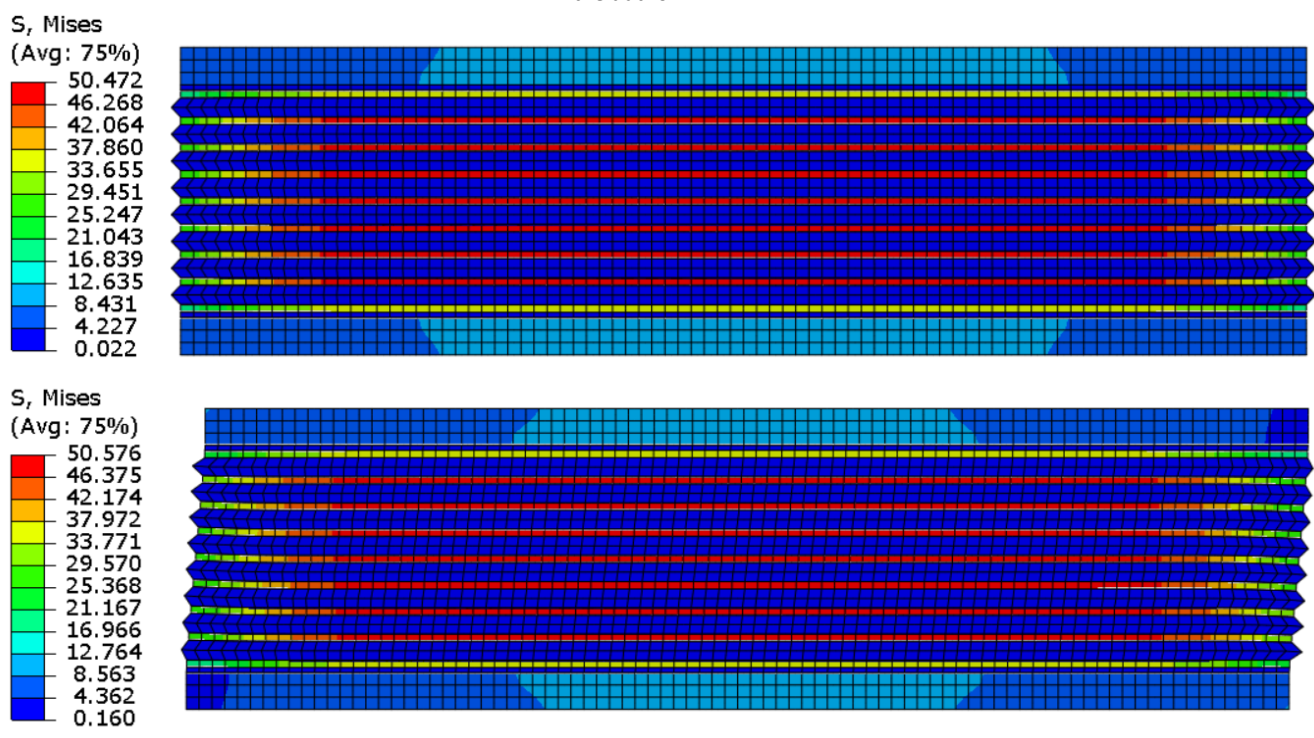

a)
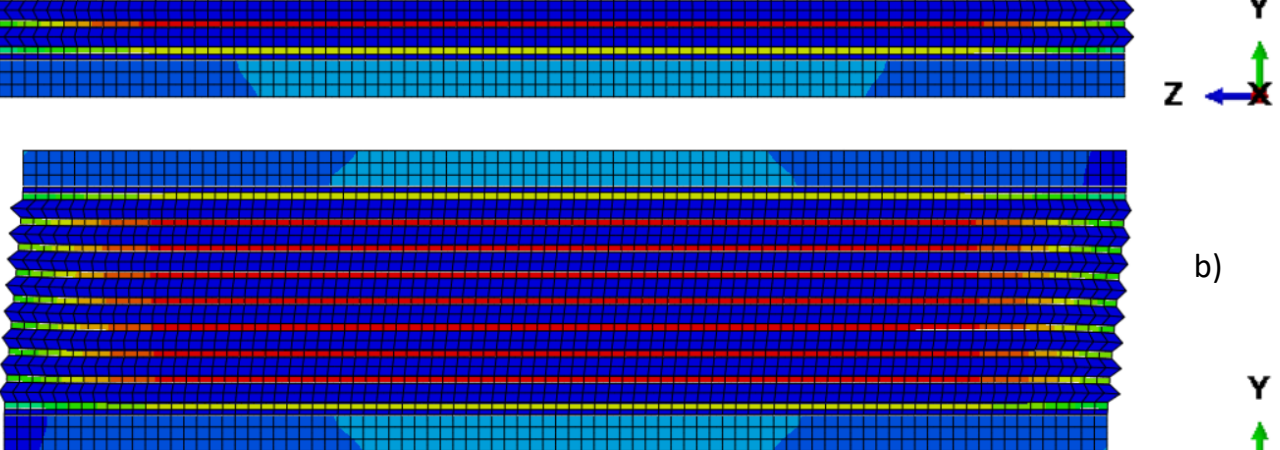

S, Mises

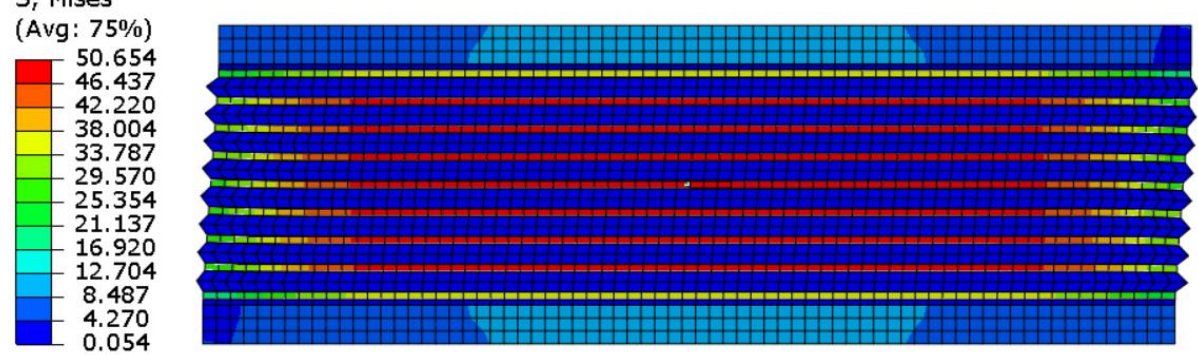

b)

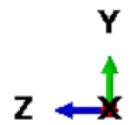

c)

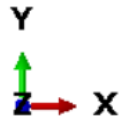

Analyzing the stress distribution, the importance of steel plates was observed since these layers concentrate the highest stresses. On the other hand, the rubber layers presented smaller stresses (about $5 \%$ of what occurs in steel), presenting pronounced deformations of the bearing pad's contour, especially in layers close to connections with structure (considered as rigid parts).

Regarding the strain observed at the end of step 3, steel reached the greatest deformation of $0.015 \%$ while the rubber reached $50 \%$ even under extremely lower stresses than observed in steel layers. These results point to the resistive characteristic of steel and the flexibility of rubber observed in the relationship between maximum stresses and strains presented in each material. Figure 5 presents the maximum normal stress-strain curves observed on the vertical axis (y), where the loads of higher magnitude are considered (structure and traffic vehicles weight).

Figure 5. Maximum Stress (MPa) $x$ strain observed in steel and rubber. Source: Developed by the author.

\section{Maximun Stress x Strain - Steel}

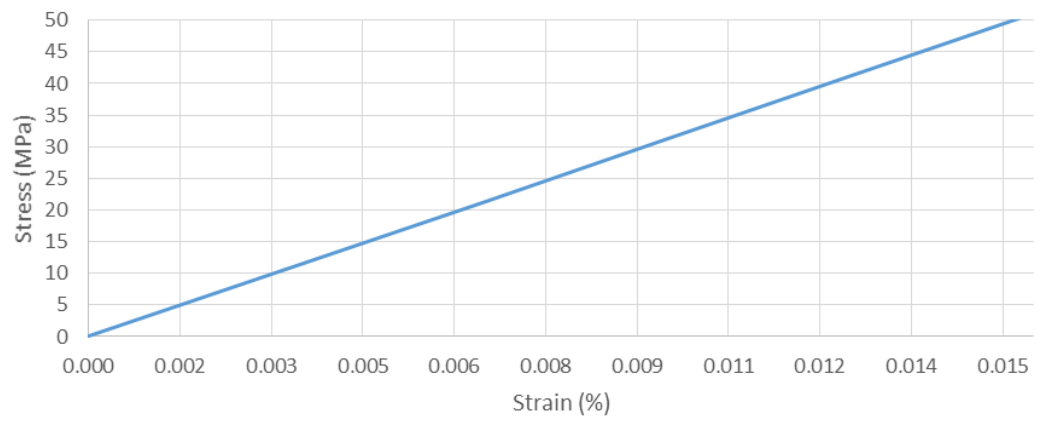




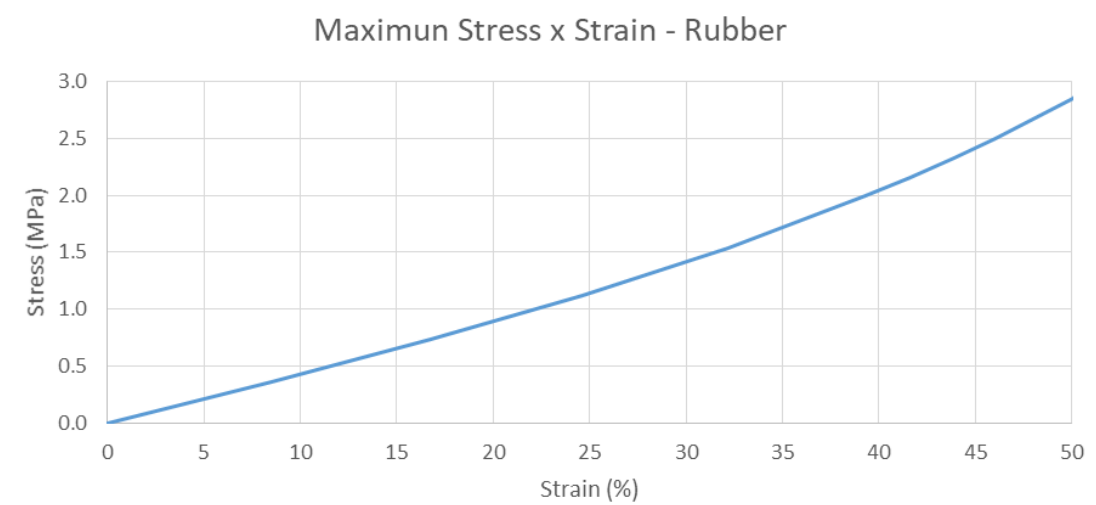

The technical code EN (20005), as demonstrated in Gajewski et al. (2015), gives a stress limitation in steel plates under compression of about $33 \%$ of the plastic limit. In this simulation, a maximum limit of $22 \%$ was obtained, not reaching the code limit.

The technical code ABNT (2015), presents a limit for compression stresses in bearing pads with widths larger than $30 \mathrm{~cm}$ as $15 \mathrm{MPa}$. When the contact area of the pad is $500 \times 600 \mathrm{~cm}$ and vertical load is $3529.8 \mathrm{kN}$, the compression stress results in $11.77 \mathrm{MPa}$. In this case, the stress is smaller than the normative requirement limit.

In the same Brazilian standard, there is a limitation associated with displacements caused by vertical and horizontal loads. Regarding vertical displacements, assuming the sum of thickness of all rubber layers as $94 \mathrm{~mm}$, the load when applied vertically results in a displacement of about $6.25 \%$ of that value, and the limit in standard is $15 \%$. The longitudinal load resulted in a displacement of $11 \%$, while transversal load reached $9 \%$, both assuming the sum of thicknesses of elastomer as a reference. For horizontal loads, the limit allowed by standard is $50 \%$.

Regarding the mechanical properties of elastomer, using the formulations of the adopted constitutive model, it appears that the initial shear modulus of the material $\left(\mu_{0}\right)$ is $1.21 \mathrm{MPa}$. Considering that Young's modulus is approximately three times that value, results should be close to $E_{0}=3.63 \mathrm{MPa}$. The bulk modulus, considering $v=0.4975$, reaches $241.6 \mathrm{MPa}$. When Poisson's ratio approaches 0.5 , the bulk modulus $k o$ are greater. In the case of incompressible materials $(v=0.5)$ this value tends to infinity.

The elastomeric pad used in this study was not compared to experimental tests in order to allow the validation of the presented results. An alternative to evaluate those responses is observed in Gent (2012), which provides an analytical method for obtaining displacements in elastomeric pads based on the equations:

$$
\frac{F_{C}}{d_{c}}=\frac{A \cdot E_{C}}{N \cdot t} ; \frac{F_{S}}{d_{s}}=\frac{A \cdot \mu}{N \cdot t}
$$

where $F_{c}$ and $F_{S}$ are compression and shear loads, $d_{c}$ and $d_{s}$ are compression and shear displacements, $\mathrm{N}$ corresponds to rubber layers, $\mathrm{t}$ to rubber thickness and $\mathrm{A}$ to pad area.

The effective compression modulus $\left(E_{c}\right)$ and shape factor $(S)$ are given by:

$$
E_{C}=E\left(1+\varphi S^{2}\right) ; S=\frac{A}{A_{B}}=\frac{L \cdot C}{2 t(L+C)}
$$

Assuming a minimum shear modulus by technical code ABNT (2015) as $1 \mathrm{MPa}$, the mechanical properties assumed in the formulations are shown in Table 2, adapted from the author's original material mentioned above:

Table 2. Material properties assumed for rubber. Source: Adapted from (Gent, 2012).

\begin{tabular}{cccc}
\hline $\begin{array}{c}\text { Shear modulus } \mu_{0} \\
(\mathrm{MPa})\end{array}$ & $\begin{array}{c}\text { Young's modulus } E_{0} \\
(\mathrm{MPa})\end{array}$ & $\begin{array}{c}\text { Bulk modulus } k_{0} \\
(\mathrm{MPa})\end{array}$ & $\begin{array}{c}\text { Compressibility } \\
\text { coefficient } \phi\end{array}$ \\
\hline 1.034 & 4.344 & 1124 & 0.57 \\
\hline
\end{tabular}

Thus, the displacements obtained at each loading phase associated with responses obtained by software present a satisfactory approximation, as shown in Table 3: 
Table 3. Displacements observed in final steps: Abaqus x Analytical method. Source: Developed by the author.

\begin{tabular}{cccc}
\multicolumn{4}{c}{ Table 3. Displacements observed in final steps: Abaqus x Analytical method. Source: Developed by the author. } \\
\hline Analysis & $\begin{array}{c}\text { Step } 1 \\
\mathrm{y}-(\mathrm{mm})\end{array}$ & $\begin{array}{c}\text { Step 2 } \\
\mathrm{z}-(\mathrm{mm})\end{array}$ & $\begin{array}{c}\text { Step 3 } \\
\mathrm{x}-(\mathrm{mm})\end{array}$ \\
\hline Abaqus & 5.87 & 10.36 & 8.43 \\
Analytic & 5.75 & 10.94 & 8.57 \\
\hline
\end{tabular}

Made up of steel and rubber, elastomeric bearing pads need to be correctly dimensioned to guarantee safety for structures, providing the transmission of vertical forces and internally working lateral deformations of these structures.

Due to the complexity involved in experimental tests, uniaxial tension is more popular, often being the only one available in this analysis. The use of data fitting technique using finite element method estimates the response of each hyperelastic model by correlating it with the tests' responses in order to select the appropriate model.

The use of constitutive models based on first invariant only are more indicated when just one experimental test is available, presenting satisfactory responses. Among the three models tested, Yeoh model was selected for presenting less variation in fitting data.

Applying the Yeoh model in elastomeric bearing pad, the equivalent von Mises stresses and displacements obtained were lower than the limits set by Brazilian and European standards, proving that geometry and arrangement of steel and rubber layers are according to normative requirements.

An analysis by analytical method shows displacement results similar to that obtained from software anlysis. However, results related to stresses are not predicted by analytical method, which shows the contribution of numerical computational models in the study of rubber materials.

In future studies it is suggested to analyze the bearing pad subjected to dynamic loads associated with traffic, which is considered in this study as static loads. In this case, the viscoelastic behavior of the elastomeric material must be considered.

\section{Acknowledgments}

The authors are grateful for the financial support granted by Fundação de Amparo à Pesquisa do Estado de Minas Gerais (FAPEMIG) and Conselho Nacional de Desenvolvimento Científico e Tecnológico (CNPq), under grants TEC PPM-00444$18,302597 / 2019-0$ and 405183/2018-6.

ABNT (2015). Associação brasileira de normas técnicas ABNT NBR 19783. Aparelhos de apoio de elastômero fretado - Especificação e métodos de ensaio. Rio de Janeiro, Brasil. (in portuguese)

Al-anany, Y. M., \& Tait, M. J. (2017). Experimental assessment of utilizing fiber reinforced elastomeric isolators as bearings for bridge applications. Composites Part B: Engineering, 114, 373-385.

Arruda, E. M., \& Boyce, M. C. (1993). A three-dimensional constitutive model for the large stretch behavior of rubber elastic materials. Journal of Mechanics and Physics of Solids, 41, 389-412.

ASTM. (2016). American society for testing and materials D412. Standard Test Methods for Vulcanized Rubber and Thermoplastic Elastomers Tension. West Conshohocken, ASTM International. West Conshohocken, PA.

Berselli, G., Vertechy, R, R., \& Pellicciari, M, M. (2011). Hyperelastic modeling of rubber-like photopolymers for additive manufacturing processes, in Rapid Prototyping Technology - Principles and Functional Requirements, Hoque, M. (Ed.), IntechOpen.

Cao, J., Ding, X.-F., Yin, Z.-N., \& Xiao, H. (2017). Large elastic deformations of soft solids up to failure: new hyperelastic models with error estimation. Acta Mechanica, 228(3), 1165-1175. 
Cardoso, C., Fernandes, C. S., Lima, R., \& Ribeiro, J. (2018). Biomechanical analysis of PDMS channels using different hyperelastic numerical constitutive models. Mechanics Research Communications, 90, 26-33.

EN, (2005). European standart EN 1337. Structural bearings - Part 3: Elastomeric bearings. Bucharest, Romania.

Gajewski, M., Szczerba, R., \& Jemiolo, S. (2015). Modelling of elastomeric bearings with application of Yeoh hyperelastic material model. Procedia Engineering 111, 220-227.

Gauron, O., Saidou, A., Busson, A., Henrique, G., \& Paultre, P. (2018). Experimental determination of the lateral stability and shear failure limit states of bridge rubber bearings. Engineering Structures, 174, 39-48.

Gent, A. N. (2012). Engineering with rubber: how to design rubber components. 3nd ed. Alan N. Gent - Ohio, USA. Ohio, USA: Alan N. Gent.

Huang, W., Xu, X., Wang, K., \& Liu, W. (2018). Numerical Simulation of Steel-Laminated Bearing Considering Friction Slipping. International Journal of Engineering and Technology, 10, 162-166.

Huang, W., Xu, X., Wang, T., Wang, K., \& Liu, W. (2019). Study on Mechanical Property of Bridge Bearings under Eccentric Compression and Shearing. International Journal of Structural and Civil Engineering Research, 8, 265-269.

Islam, A. M. (2017). Evaluation of story response in seismic prone building construction using high damping rubber bearing. Revista de la Construcción, 17, 354-363.

Kalfas, K. N., Mitoulis, S. A., \& Katakalos, k. (2016). Numerical study on the response of steel-laminated elastomeric bearings subjected to variable axial loads and development of local tensile stresses. Engineering Structures, 134, 346-357.

Lalo, D. F., Greco, M., \& Meroniuc, M. (2019). Numerical modeling and experimental characterization of carbon-black filled rubber models under viscoelastic effects through bulge test implementation for biaxial training. Mathematical Problems in Engineering, 2019, Article ID 5182629, 114.

Lee, H. S., Shin, J. K., Msolli, S., \& Kim, H. S. (2017). Prediction of the dynamic equivalent stiffness for a rubber bushing using the finite element method and empirical modeling. International Journal of Mechanics and Materials in Design, 15(1),1-15.

Marlow, R. S. (2003). A General First-Invariant Hyperelastic Constitutive Model. Constitutive Models for Rubber III, 157-160.

Mansouri, M. R., Darijani, H., \& Baghani, M. (2017). On the Correlation of FEM and Experiments for Hyperelastic Elastomers. Experimental Mechanics, 57(2), 195-206.

Miller, K. (2004). Testing Elastomers for Hyperelastic Material Models in Finite Element Analysis. Testing and Analysis. Axel Products.

Mooney, M. (1940). A theory of large elastic deformation. Journal of Applied Physics, 11, 582-592.

Ogden, R. W. (1972). Large deformation isotropic elasticity. On the correlation of theory and experiment for incompressible rubber-like solids. Philosophical Transactions of the Royal Society of London - Series A, 326, 565-584.

Ogden, R. W. (1984). Non-Linear Elastic Deformations. Chichester: Harwood Series Mathematics and its Applications.

Shuijiang, W. (2018). Numerical calculation of bridge seismic response considering beam-block collision effect. Revista de la Construcción, 18, 111122.

Simulia (2013). Abaqus analysis user's manual. Version 6.13 - Dassault Systems.

Stanton, J. F., \& Roeder, C. W. (1982). NCHRP Report 248: Elastomeric Bearings Design, Construction, and Materials. Washington DC: Transportation Research Board.

Tavares, J. M. (1998). Introdução ao método dos Elementos Finitos. Porto / Portugal: FEUP.

Treloar, L. R. (1943). The elasticity of a network of long-chain molecules I. Transactions of the Faraday Society, 39, 36-41.

Treloar, L. R. (1943). The elasticity of a network of long-chain molecules II. Transactions of the Faraday Society, 39, $241-246$.

Treloar, L. R. (1975). The Physics of Rubber Elasticity. London: Oxford University Press.

Valanis, K. C., \& Landel, R. F. (1967). Strain-energy function of a hyper-elastic material in terms of the extension ratios. Journal of Applied Physics, 38, 2997-3002.

Yeoh, O. H. (1993). Some forms of the strain energy function for rubber. Rubber Chemistry and Technology, 66, $754-771$. 